\title{
Review
}

\section{Tumour-stromal interactions}

\section{Transforming growth factor- $\beta$ isoforms and hepatocyte growth factor/scatter factor in mammary gland ductal morphogenesis}

\author{
Jeffrey W Pollard
}

Departments of Developmental and Molecular Biology, and OB/GYN and Women's Health, Center for the Study of Reproductive Biology and Women's Health, Albert Einstein College of Medicine, New York, New York, USA

\begin{abstract}
Correspondence: Jeffrey W Pollard, Department of Developmental and Molecular Biology, Center for the Study of Reproductive Biology and Women's Health, Albert Einstein College of Medicine, 1300 Morris Park Ave, New York, NY 10461, USA. Tel: +1 718430 2090;

fax: +1 718430 8972; e-mail: pollard@aecom.yu.edu
\end{abstract}

Received: 5 January 2001

Revisions requested: 31 January 2001

Revisions received: 26 April 2001

Accepted: 17 May 2001

Published: 14 June 2001
Breast Cancer Res 2001, 3:230-237

(C) 2001 BioMed Central Ltd

(Print ISSN 1465-5411; Online ISSN 1465-542X)

\begin{abstract}
The mammary gland undergoes morphogenesis through the entire reproductive life of mammals. In mice, ductal outgrowth from the nipple across the fat pad results in an intricate, well spaced ductal tree that further ramifies and develops alveolar structures during pregnancy. Ductal morphogenesis is regulated by the concerted action of circulating steroid and polypeptide hormones, and local epithelial-mesenchymal inductive signals. Transforming growth factor (TGF)- $\beta_{1-3}$ and hepatocyte growth factor (HGF)/scatter factor (SF) are important components of this latter signaling pathway. TGF- $\beta_{1}$ and TGF- $\beta_{3}$ have roles in both promotion and inhibition of branching morphogenesis that are dependent on concentration and context. HGF/SF promotes ductal outgrowth and tubule formation in the mammary gland. These data suggest that these two growth factors have complementary roles in promoting mammary ductal morphogenesis and in maintaining ductal spacing. In addition, TGF- $\beta_{3}$ triggers apoptosis in the alveolar epithelia, which is a necessary component of mammary gland involution and return of the ductal structure to a virgin-like state after lactation.
\end{abstract}

Keywords: apoptosis, ductal morphogenesis, growth factor, mammary gland, SMAD

\section{Introduction}

The development of the mammary gland largely occurs postnatally. Initially, the ductal system begins to develop from the nipple, and is characterized by specialized structures - the terminal end buds (TEBs) - capping the end of the ducts. TEBs grow out across the fat pad and, by bifurcation, lay down by puberty the minimally branched structure that covers the fat pad, at which point the TEBs disappear. Throughout the estrus cycle there is modest development of the ductal system, but it is during pregnancy that a dramatic outgrowth of secondary branches occurs that, together with the formation of the lobuloalveolar structures, results in the milk-producing gland. Once weaning has occurred, this fully developed structure regresses to a virgin-like state.

It has been well established that these events are under the control of a complex interplay of circulating hormones, particularly estrogen, progesterone, glucocorticoids and prolactin gene family members [1]. However, it has also become clear that local mesenchymal-epithelial interactions are essential for mammary development, and that

HGF = hepatocyte growth factor; LTGF = latent inactive precursor of transforming growth factor; MMTV = mouse mammary tumor virus; $\mathrm{SCID}=$ severe combined immunodeficiency; SF = scatter factor; TEB = terminal end bud; TGF = transforming growth factor. 


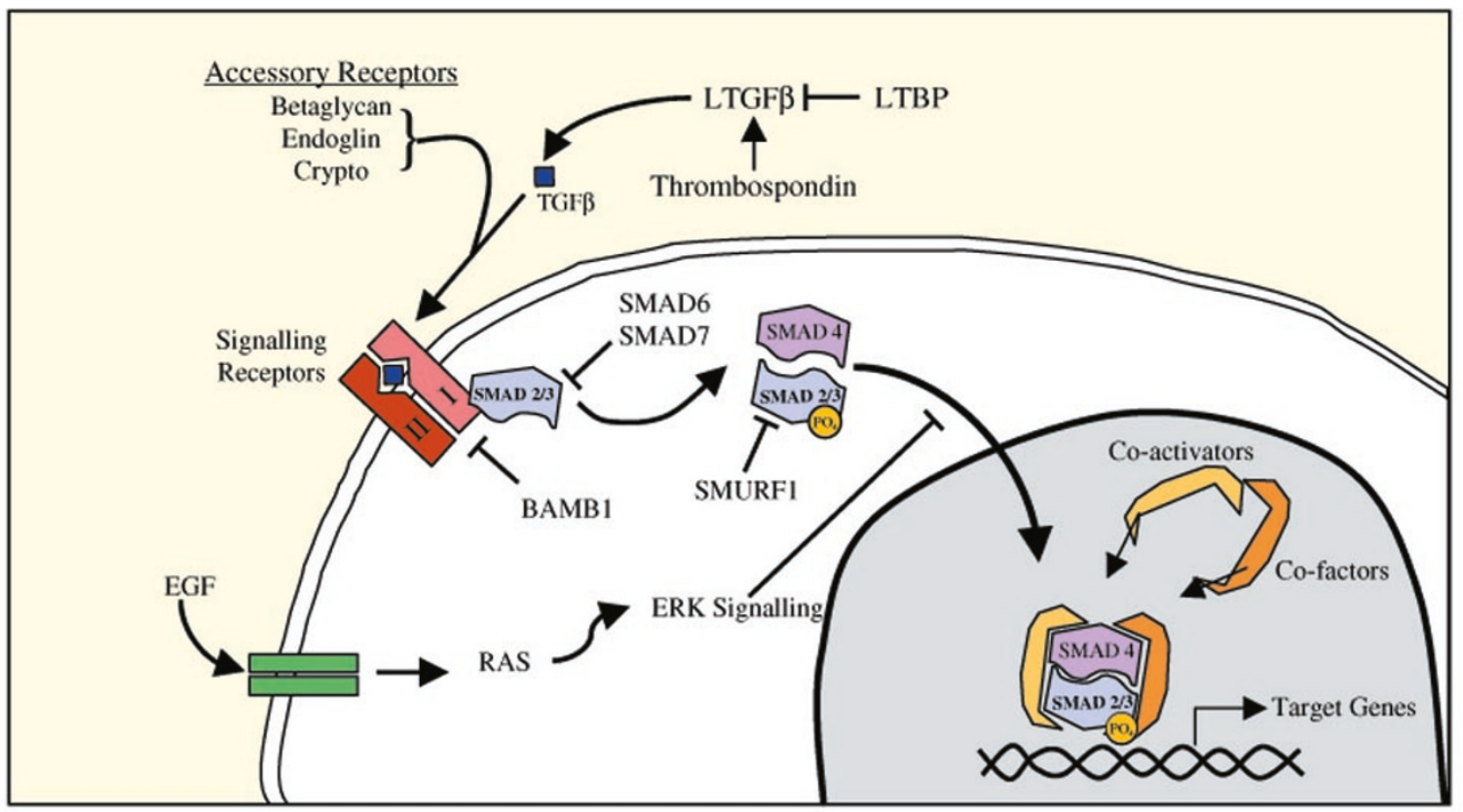

Schematic of the TGF- $\beta$ signaling pathway, showing the activation cascade and points of inhibition $(\perp)$. Active TGF- $\beta$, released from the latent complex by the action of thrombospondin, binds to the type II receptor, resulting in the formation of an active receptor-signaling complex. This binding is enhanced by accessory receptors, whereas the receptor dimerization can be inhibited by membrane-bound inhibitors such as bone morphogenic protein and activin membrane bound inhibitor (BAMBI). After ligand binding, the receptor SMADs are phosphorylated, dimerize with SMAD-4, and translocate to the nucleus where they recruit appropriate cofactors and coactivators to stimulate transcription of target genes. TGF- $\beta$ signaling can be blocked by the inhibitory SMADs, SMAD-6 and SMAD-7, which prevent receptor-SMAD activation; and by the ras pathway, which can lead to inhibition of nuclear translocation of the dimeric SMAD complex. Receptor SMADs can also be degraded following ubiquinylation by the ubiquitin ligase SMURF1. Figure adapted from Massagué [5].

many of these are mediated by growth factors that are often synthesized in response to the circulating hormones. These include wnt family proteins, TGF- $\alpha$, fibroblast growth factors, insulin-like growth factors, epidermal growth factor [2], colony stimulating factor-1 [3], and - the subjects of the present review - the TGF- $\beta$ family of proteins and HGF/SF.

\section{Transforming growth factor- $\beta$ isoforms}

The three classical members of the TGF- $\beta$ family belong to a much larger family. In humans this family contains almost 30 members, including bone morphogenic proteins, activins, and Mullerian inhibiting substance [4]. These TGF- $\beta$ family members have profound effects during development, regulating cell fate by affecting proliferation, differentiation and cell death, and therefore they are important for the development of many tissues.

All three of the classical TGF- $\beta$ isoforms (TGF- $\beta$ s) activate intracellular responses by binding to and heterodimerizing the same two transmembrane serine/threonine kinases (Fig. 1) [5]. In this complex the type II receptor phosphorylates the type I receptor (also known as activin receptor-like kinase), activation of which results in propagation of the signal intracytoplasmically to the transcription machinery. This propagation is via the direct phosphorylation of SMAD proteins [6]. Eight SMAD family members have been documented. In the case of TGF- $\beta$ s, however, SMAD-2 and SMAD-3 (or receptor phosphorylated SMADs) are the positive signaling SMADs. These phosphorylated SMADs heterodimerize with a common shared partner, SMAD-4. After this they translocate to the nucleus where, by recruitment of coactivator proteins, they participate in the transcriptional activation of target genes. In contrast, SMAD- 6 and SMAD-7 are negative regulators. SMAD-7 binds to the TGF- $\beta$-activated receptor, where it inhibits the phosphorylation of SMAD-2 and SMAD-3, consequently downregulating the signaling pathway. SMAD-7 expression is also upregulated by TGF- $\beta_{1}$, allowing it to act in an autoinhibitory feedback loop that shuts off TGF- $\beta$ signaling. Negative control also occurs by degradation of SMADs following their ubiquinylation by SMURF-1 [5].

There is also growing evidence for other postreceptor signaling pathways (probably involving the mitogen-activated protein kinase pathway) and for other cell-type specific TGF- $\beta$ receptors [6]. Furthermore, several intracellular sig- 
naling pathways interact with the TGF- $\beta$ signaling pathway to ensure cell-type specific responses through activation of different genes. Discussion of this aspect of TGF- $\beta$ biology is beyond the scope of the present review, and the reader is referred to the several recent excellent reviews on this topic $[4,5,7]$.

In order to understand the roles of TGF- $\beta$ in vivo, it is also important to appreciate that there are several extracellular controls on TGF- $\beta$ function that can spatially and temporally regulate TGF- $\beta$ action to allow context dependent action (Fig. 1). Most significantly, TGF- $\beta$ s are synthesized as latent inactive precursors of transforming growth factor (LTGF)- $\beta$, consisting of the $24-\mathrm{kDa}$ cytokine and a $80-\mathrm{kDa}$ dimer of the prepro region called the latency-associated protein. During secretion of TGF- $\beta$ s from the cell the latency-associated protein region is cleaved from the precursor molecule by Furin-mediated proteolysis, followed by a noncovalent attachment to the dimeric TGF- $\beta$. In nontransformed cells, LTGF- $\beta$ is covalently bound to LTGF- $\beta$ binding proteins (of which four distinct ones have been described) and deposited in the extracellular matrix. LTGF- $\beta$ is inactive, and therefore activation is a key mechanism in the action of TGF$\beta$; this activation is stimulated by proteases, with the majority of in vivo activation ascribed to thrombospondin-1 [8]. In addition to the availability of active TGF- $\beta$, its signaling is also regulated by membrane anchored coreceptors such as $\beta$ glycan (also called TGF- $\beta$ type III receptor), endoglin and crypto, which potentiate the binding of TGF- $\beta$ to its receptor. Thus, in vivo, a complex web of interacting proteins exerts both negative and positive controls over the action of TGF- $\beta$.

\section{Transforming growth factor- $\beta$ isoforms in the mammary gland \\ Expression patterns of transforming growth factor- $\beta$ isoforms in the mammary gland}

In the mammary gland TGF- $\beta$ s are expressed in a complex and overlapping pattern [9], suggesting important roles for them in its development. All three TGF- $\beta$ s are expressed in the epithelium of the TEBs, although TGF- $\beta_{2}$ has a very low expression at this stage, and throughout the rest of ductal development. In most ductal areas, expressions of TGF- $\beta_{1}$ and TGF- $\beta_{3}$ are overlapping. However, TGF- $\beta_{1}$ is found uniquely at the tips of the developing bud, whereas TGF- $\beta_{3}$ transcripts are found in the flanking region.

These patterns of mRNA expression are largely recapitulated by protein expression, although most studies did not distinguish active from latent TGF- $\beta$ s. Preliminary studies were conducted by Barcellos-Hoff and Ewan [10], who used antibodies that can discriminate active from latent TGF- $\beta_{1}$; those investigators showed mosaic expression of active and inactive TGF- $\beta_{1}$ in the mammary epithelium, whereas only LTGF- $\beta$ was found in the stroma. TGF- $\beta_{3}$ expression was also found uniquely in the myoepithelial cells, whereas TGF- $\beta_{1}$ was deposited in the stroma around quiescent terminal ducts.
During pregnancy, TGF- $\beta_{1}$ is expressed at low levels in alveolar and ductal structures, whereas TGF- $\beta_{2}$ has a lower but similar pattern of expression. TGF- $\beta_{3}$ is the most strongly expressed of all the isoforms in the alveolar and ductal structures. Toward the end of pregnancy and during lactation, all isoforms are heavily downregulated [9]. On weaning, however, TGF- $\beta_{3}$ mRNA and protein is dramatically upregulated in the alveolar epithelial and ductal cells $[11,12]$.

TGF- $\beta$ receptor II expression is found in the ductal epithelial and surrounding stromal cells in virgin, pregnant, and involuting mammary gland. Similarly, in situ hybridization localized TGF- $\beta$ receptor I (activin receptor-like kinase 5) to the same cells at all these stages of development [13], suggesting that both epithelial and mesenchymal cells can respond to endogenous TGF- $\beta$.

\section{Modes of action of transforming growth factor- $\beta$ isoforms in the mammary gland}

Experiments that have introduced TGF- $\beta$ s into the mammary gland by implantation or via transgenic means have largely suggested that TGF- $\beta_{1}$ is a growth inhibitor, suppressing ductal morphogenesis (Table 1). The first experiments of this type employed the implantation of slowrelease pellets containing TGF- $\beta$ s into the mammary fat pad [14]. All three TGF- $\beta$ isoforms suppressed TEB formation (in a reversible manner), causing the ends of the ducts to take on the appearance of growth-quiescent ducts [9]. Expression of constitutively active TGF- $\beta_{1}$ from the mouse mammary tumor virus (MMTV) promoter resulted in a hypoplastic ductal tree, but with no effect on lobuloalveolar development [15]. In contrast, TGF- $\beta_{1}$ expressed from the later acting whey acidic protein promoter inhibited alveolar, but not ductal development during pregnancy [16]. This was associated with a reduction in the stem cell pool available for lobuloalveolar development [17].

More recently transgenic techniques have been employed to express dominant-negative forms of the TGF- $\beta$ receptor, which are aimed at inhibition of all TGF- $\beta$ isoform signaling in the mammary gland. Expression of such a dominant-negative construct in the mammary epithelium from the MMTV promoter resulted in precocious alveolar hyperplasia in virgin mice, but without any effect on TEB formation [18]. Expression of the same construct primarily in mammary stromal cells, however, caused an increase in lateral branching, suggesting that these stromal cells were the primary sites of action of epithelial expressed TGF- $\beta$ s [13]. This is consistent with observations that TGF- $\beta_{1}$ slow-release implants in cleared fat pads suppressed the formation of new end buds in transplanted mammary epithelium [19]. Together, these experiments are in line with roles for TGF- $\beta_{1}$ and TGF- $\beta_{3}$ in the maintenance of ductal spacing by inhibition of lateral branching through epithelial-mesenchymal signaling (Fig. 2). 
Table 1

\begin{tabular}{|c|c|c|c|}
\hline Experimental design & Cell type expression*/tissue affected ${ }^{\dagger}$ & Phenotype & Reference \\
\hline \multicolumn{4}{|l|}{ Gain of function } \\
\hline MMTV-TGF- $\beta_{1}$ & Mammary epithelium & Inhibition of ductal development & {$[15]$} \\
\hline WAP-TGF- $\beta_{1}$ & Lobuloalveolar progenitors and cells & $\begin{array}{l}\text { Inhibition of alveolar development; } \\
\text { aging of stem cells }\end{array}$ & [17] \\
\hline$\beta$-lactoglobulin- TGF- $\beta_{3}$ & $\begin{array}{l}\text { Alveolar and ductal epithelial cells during } \\
\text { lactation }\end{array}$ & Induction of apoptosis & [12] \\
\hline Retroviral HGF & $\begin{array}{l}\text { Primary mammary epithelial cells } \\
\text { transplanted into the mammary fat pad }\end{array}$ & Increased TEB number and branching & [32] \\
\hline \multicolumn{4}{|l|}{ Loss of function } \\
\hline MMTV-dnTGF- $\beta$ receptor II & Mammary epithelium & $\begin{array}{l}\text { Precocious lobuloalveolar development } \\
\text { and milk production }\end{array}$ & [18] \\
\hline MMTV-dnTGF- $\beta$ receptor II & Mammary stroma & Increased lateral branching & [13] \\
\hline TGF- $\beta_{1}{ }^{-/-}$SCID & Whole animal & Hypoplastic ductal tree & $\begin{array}{l}\text { Ingram W, Robertson SA, } \\
\text { personal communication }\end{array}$ \\
\hline TGF- $\beta_{1}^{+/-} \mathrm{p} 21^{-/-}$ & Whole animal & $\begin{array}{l}\text { Accelerated mammary development; } \\
\text { normal adult structure }\end{array}$ & [10] \\
\hline SMAD-3-/- & Whole animal & Hypoplastic mammary epithelium & [21] \\
\hline TGF- $\beta_{3}{ }^{-1-}$ & Mammary epithelium into wild-type stroma & $\begin{array}{l}\text { Reduced apoptosis during involution. } \\
\text { Normal mammary development }\end{array}$ & [12] \\
\hline dnMet & $\begin{array}{l}\text { Mammary tumor cells in culture followed } \\
\text { by transplantation to mice }\end{array}$ & Increased tubule formation & [30] \\
\hline
\end{tabular}

${ }^{*}$ For gain of function. ${ }^{\dagger}$ For loss of function. dn, dominant negative. MMTV, mouse mammary tumor virus; WAP = whey acidic protein.

\section{Insights gained from transforming growth factor- $\beta$ gene knockout mice}

Considerable insights into biologic processes have been gained by the generation of null mutations in mice (Table 1). All three TGF- $\beta$ genes have been mutated, as have their receptors, several SMAD genes, and LTGF- $\beta$ binding proteins [20]. Generally, these experiments were uninformative regarding mammary development. Perhaps the greatest insights might have come from targeted ablation of the SMAD genes. Unfortunately, SMAD-4- and SMAD-2-null mutant mice die very early in gestation, precluding mammary gland studies. However, SMAD-3-/mice survive up to eight weeks of age. Detailed analysis of mammary development has yet to be reported [20], although a preliminary analysis [21] suggested that the mammary glands are under-developed.

The TGF- $\beta_{1}$-null phenotype is variable, with many mice dying during embryogenesis due to vasculature defects, although in some cases they die within a few days of life because of multifocal inflammatory lesions. However, these mice can be maintained if they are crossed with severe combined immunodeficiency (SCID) mice [20], or with mice that are nullizygous for the cell cycle inhibitor p21 [21]. Preliminary analysis of mammary development in
TGF- $\beta_{1}^{-1-}$ SCID mice shows a dramatic reduction in ductal complexity, suggesting an essential role for TGF- $\beta_{1}$ in ductal outgrowth (Ingman WV, Robertson SA, personal communication). Interestingly, on the $p 21^{-/-}$background, TGF- $\beta_{1}{ }^{+/-}$mice (in which TGF- $\beta_{1}$ concentrations are significantly reduced) show accelerated mammary development [10]. TGF- $\beta_{3}$-null mutant mice also die at birth, but transplantation of their rudimentary mammary glands into recipient SCID mice allowed mammary development to be assessed. This did not reveal any gross defects in branching morphogenesis, however, and the glands apparently developed normally through to lactation [12].

At first sight these results on the mammary gland development of TGF- $\beta_{1}$-null and TGF- $\beta_{3}$-null mutant mice are difficult to reconcile with the experiments described above suggesting inhibitory roles for TGF- $\beta$ s in the branching morphogenesis of this organ. However, in cultures of TAC-2.1 mammary cells, low concentrations of TGF- $\beta_{1}$ had a positive effect on tubule and branching formation that was coincident with the inhibition of colony formation, whereas high concentrations only inhibited colony formation and had no effect on morphogenesis. Low concentrations also stimulated cell proliferation, whereas high doses inhibited this parameter, an effect 


\section{Figure 2}

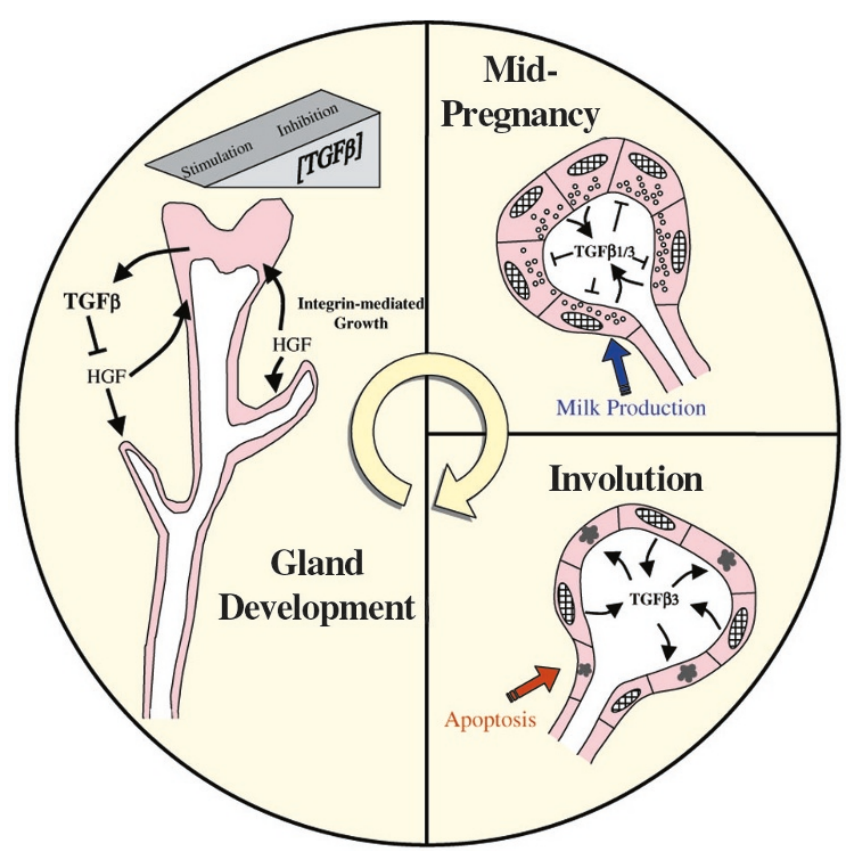

Postulated roles for TGF- $\beta$ and HGF/SF during the life cycle of the mammary gland. TGF- $\beta$ s have complex roles during mammary development, according to their concentration. Although most of the experimental evidence points to inhibition of ductal branching, preliminary analysis of both TGF- $\beta_{1}$ - and SMAD-3-null mutant mice suggest a requirement for TGF- $\beta_{1}$ for mammary development. Thus, TGF- $\beta$ s have both concentration- and context-dependent effects on mammary gland development. HGF/SF promotes ductal outgrowth through an integrin-mediated process. This action is inhibited by TGF- $\beta_{1}$, indicating that interactions between these growth factors play a role in ductal spacing as the mammary gland grows out over the fat pad. During pregnancy, TGF- $\beta$ s appear to inhibit alveolar development and suppress milk formation. The decline in TGF- $\beta$ expression at the end of pregnancy appears to be necessary for full lobuloalveolar development and lactation. After weaning involution is begun, with TGF- $\beta_{3}$ inducing apoptosis in the lobuloalveolar structures through an autocrine mechanism.

that was dependent on the extracellular matrix [22]. Thus, TGF- $\beta$ s might promote the outgrowth of TEBs and lateral branches at low concentration, whereas higher concentrations suppress growth in terminal end ducts and along the ductal length, perhaps by inhibiting expression or action of HGF/SF, as has been reported in culture [23] (Fig. 2). These conclusions would be consistent with the opposite effects on mammary development observed in mice with one or two mutant alleles of TGF- $\beta_{1}$. Confirmation of this interpretation will await detailed studies on the mammary glands of the homozygous and heterozygous mutants. This by necessity will involve mammary gland transplantation in order to confirm that the effects of the mutations are organ autonomous.
Toward the end of pregnancy TGF- $\beta$ expression is dramatically downregulated, with very low levels of TGF- $\beta_{2}$ mRNA detected during lactation $[9,11,12]$. Milk protein expression by mammary epithelial cells in culture, in response to lactogenic hormones, is suppressed by TGF- $\beta_{1}[24,25]$. Expression of a TGF- $\beta$ receptor II dominant-negative transgene in the mammary epithelium resulted in premature expression of casein [18]. These results, together with those regarding over-expression of TGF- $\beta_{1}$ from the whey acidic protein promoter (Table 1) [18], suggest that another role for TGF- $\beta$ s is to regulate lobuloalveolar development and suppress milk production during pregnancy. These effects are alleviated by downregulation of these proteins toward the end of pregnancy, such that the full development of the mammary gland during lactation is permitted (Fig. 2).

Immediately after weaning, expression of TGF- $\beta_{3}$ is dramatically induced in the alveolar epithelium in a pattern that precedes the onset of apoptosis and that persists for several days at a lower, but still significant level $[11,12]$. Transgenic over-expression of TGF- $\beta_{3}$ during lactation induced alveolar epithelial apoptosis without causing gland involution. TGF- $\beta_{3}$-null mutant mammary epithelial tissue transplanted into the cleared fat pad of a wild-type recipient developed and underwent lactation, but on weaning the tissue showed a lower rate of apoptosis than that in wild-type control tissue, but without a complete ablation of this response. Analysis of SMAD-4 nuclear association indicated that the alveolar epithelium was the target for TGF- $\beta_{3}$ acting through an autocrine mechanism. This induction of TGF- $\beta_{3}$ was in response to milk stasis rather than changes in the hormonal milieu. Together the data provide compelling evidence that TGF- $\beta_{3}$ is one of the mammary-derived signals that induce apoptosis during the first phase of involution [12] (Fig. 2).

\section{Hepatocyte growth factor/scatter factor}

HGF/SF, originally identified by its motogenic activity on cultured cells, is a pleiotropic cytokine that promotes survival and proliferation in a wide variety of cells. It also has dramatic effects on cell morphology, triggering intrinsic morphogenic events such as tubule formation in many epithelial cell lines, including those from the mammary gland. It binds to and signals through a unique transmembrane tyrosine kinase receptor, the product of the c-met proto-oncogene. In general, the c-met oncogene is expressed in epithelial cells, whereas the ligand is expressed in the surrounding mesenchyme, providing a mechanism for the epithelial-mesenchymal inductive processes during development. HGF/SF receptor signals in large part via the ras signaling pathway initially after binding the docking protein Grb2, which is essential for cmet signaling [26]. HGF/SF also binds to the extracellular matrix, and heparan sulfate proteoglycans potentiate HGF/SF signaling [27]. 
Ductal morphogenesis and branching of the resultant tubules can be induced by HGF/SF in primary and certain established mammary epithelial cells cultured in collagen gels or matrigel $[23,28,29]$. Expression of a dominantnegative c-met receptor can also reverse the tumorigenic phenotype of DN-DA3 mouse mammary adenocarcinoma cell line after transplantation into nude mice, causing them to adopt a differentiated phenotype that is characterized by extensive tubule formation [30]. HGF/SF is synthesized in the mammary stroma, probably by fibroblasts, and acts on receptor-expressing ductal epithelial cells [23]. Together these experiments strongly suggest that HGF/SF c-met signaling is a classical epithelial-mesenchymal inductive pathway that is important for ductal morphogenesis in the mammary gland (Fig. 2). Despite their dramatic nature, however, a caveat of the culture experiments is that the cells form unilaminar tubes that do not resemble the elaborate TEBs that are the primary growth point and determinant of branching in the developing mammary gland.

Unfortunately, null mutants in both HGF/SF and c-met genes in mice cause embryonic lethality because of placental insufficiency and developmental defects in the liver and muscle [31]. Over-expression of HGF/SF or c-met in the mammary epithelium resulted in hyperplasia and tumorigenesis, but the effects on early mammary development were not assessed [23]. In order to overcome these problems, Yant et al [32] transfected primary mouse mammary epithelial cells with a retrovirus containing HGF/SF cDNA, and transplanted these into a cleared recipient fat pad. This increased TEB size and number, and resulted in a hyperplastic ductal tree. These data are consistent with a positive role for HGF/SF in ductal morphogenesis (Fig. 2).

\section{Conclusion}

The exquisitely branched structure of the mammary gland requires sophisticated positional clues to maintain ductal spacing. TEBs, with their unique club-shaped multilaminar structures, are both the growth and branching decision points for the developing mammary gland in mice. These structures are encased in a basement membrane, and during their growth they recruit around their body a unique stroma that includes macrophages, eosinophils, and fibroblasts. Unexpectedly, both macrophages and eosinophils appear to regulate ductal morphogenesis, because this process is inhibited in mouse mutants that reduce the abundance of these cells in the mammary gland [3]. Interestingly, macrophages can both produce and respond to TGF- $\beta$ s, suggesting that these migratory cells could locally and transiently modify the responsiveness of the tissue to these factors. For example, TGF- $\beta_{1}$ inhibits cytokine induction of matrix metalloproteinase-12 in macrophages [33], possibly limiting their ability to remodel matrix and thereby suppressing lateral branching.
Furthermore, macrophages have been shown to activate LTGF- $\beta_{1}$ following binding to cell surface expressed $\beta$ glycan [34]. Thus, it may be speculated that at least part of the role of macrophages in regulating branching morphogenesis is to activate epithelial cell-derived TGF- $\beta_{1}$ and, in turn, to have their remodeling functions modified by TGF- $\beta_{1}$ in a very precise pattern. This is consistent with the role of TGF- $\beta_{1}$ in matrix remodeling after radiationinduced damage of the mammary gland [35].

The epithelial cells of the TEBs also need to migrate through the stroma as they grow out across the fat pad. TGF- $\beta_{1}$ can also reversibly induce trans-differentiation of mammary epithelial cells to mesenchyme-like cells that may be important in the migration of cells during TEB outgrowth [36]. Perturbation of $\beta_{1}$-integrin signaling by blocking antibodies affects TEB formation and inhibits mammary gland development [37]. Anti- $\beta_{1}$-integrin antibodies blocked HGF/SF-induced tubulogenesis in cultures of mammary epithelial cells, suggesting that HGF/SF signals to the integrin pathways to promote cellular adhesion during ductal morphogenesis [37]. A major effect of TGF- $\beta s$ is to modulate matrix deposition by fibroblasts, cells that are found around the TEB. This suggests that TGF- $\beta$ s and HGF/SF may co-operate in the regulation of the migration of epithelial cells across the fatty stroma by altering integrin-matrix signaling locally. Furthermore, in other tissues TGF- $\beta$ s play an important role in angiogenesis [38], a process that is assumed to be essential for ductal outgrowth and necessary for mammary gland function. Thus, it is likely that TGF- $\beta$ s locally regulate angiogenesis to accommodate the developing mammary gland.

In addition to these effects of TGF- $\beta$ s on the stroma, at probably higher concentrations TGF- $\beta$ s inhibit ductal development through their cell cycle inhibitory effects on epithelial cells. There is considerable understanding, particularly in mammary epithelial cells in culture, of the intracellular pathways that mediate the growth inhibitory properties of TGF- $\beta_{1}$. TGF- $\beta_{1}$ maintains the retinoblastoma protein in its cell cycle inhibitory hypophosphorylated state through the induction of the cyclin-dependent inhibitors $p 15^{\text {ink } 4 b}$ and p21 cip//waf1 and the downregulation of cyclin-dependent kinase 2 phosphatase cdc25A [4]. The early signal transduction pathways via SMAD-2, -3 , and -4 are also well documented [4]. In contrast, HGF/SF promotes epithelial cellular proliferation and ductal outgrowth in culture. Its signal transduction pathway through the c-met receptor has also been well studied [31]. In fact, a downstream kinase target, Gab1, of this receptor mimicked the action of HGF/SF on tubule formation when transfected into cultured $\mathrm{EpH} 4$ mouse mammary epithelial cells [28].

Most of this information on HGF/SF and TGF- $\beta$ signal transduction has been derived from cells in culture, however, and has not been extrapolated to, or confirmed 
in the mammary gland in vivo. Considerable insight could therefore be obtained by analysis of these signaling pathways in the mammary gland during development. This is especially important given the multiple levels of control over TGF- $\beta$ and HGF action. It is essential to define sites of TGF- $\beta_{1}$ and HGF/SF signaling. A powerful tool in this approach will be use of the immunolocalization of nuclear SMAD-4 and of antiphosphorylation specific anti-c-met antibodies as surrogate markers within cells for TGF- $\beta$ receptor and c-met activation, respectively. These studies could help define the temporal and spatial requirements in different cell types throughout the development of the mammary gland. Similarly, conditional ablation of specific signaling molecules in particular cell types in the mammary gland could reveal individual functions for these growth factors. Allelic series of mutants can also reveal differential functions, as was elegantly shown for oncogenic signaling during mammary gland cancer [39] and for the role of the Grb2 binding site on the c-met receptor that was specifically required for its function in muscle, but not placental or liver development [31].

HGF/SF and TGF- $\beta$ s appear to have important roles in branching morphogenesis, lobuloalveolar development, and involution in mice. Similar expression patterns in other species, including human, argue for similar roles in these organisms $[40,41]$. These growth factors integrate within a complex web of growth factor and hormone signaling to pattern the ductal tree. These include other members of the TGF- $\beta$ family, such as activins and inhibins [1], as well as other growth factors that influence mammary gland development, such as insulin-like growth factor-1, which has also recently been shown to modulate TGF- $\beta_{1}$ expression in this organ [42]. The complexity of the responses and the multiple levels of regulation, including the presence of latent forms and extracellular binding proteins, suggest that cell culture experiments will be inadequate to tease out the different roles for these proteins. Only sophisticated genetic experiments in vivo, coupled with the unique ability of the mammary gland elements to be transplanted between genotypes, can provide causality for the involvement of TGF- $\beta$ s and HGF/SF in different aspects of mammary gland morphogenesis and function.

\section{Acknowledgement}

I thank Dr A Mackler for help with the figures. This work was supported by NIH grant HD30280 to JWP and the Albert Einstein Comprehensive Cancer Center Grant P30-CA13330.

\section{References}

1. Hennighausen L, Robinson GW: Think globally, act locally: the making of a mouse mammary gland. Genes Dev 1998, 12: 449-455.

2. Woodward T, Xie J, Haslam S: The role of mammary stroma in modulating the proliferative response to ovarian hormones in the normal mammary gland. I Mam Gland Biol Neoplasia 1998, 3:117-131.

3. Gouon-Evans V, Rothenberg ME, Pollard JW: Postnatal mammary gland development requires macrophages and eosinophils. Development 2000, 127:2269-2282.
4. Massague J, Blain SW, Lo RS: TGFbeta signaling in growth control, cancer, and heritable disorders. Cell 2000, 103: 295-309.

5. Massagué J: How cells read TGF-beta signals. Nature Rev Mol Cell Biol 2000, 1:169-178.

6. Itoh S, Itoh F, Goumans MJ, Ten Dijke P: Signaling of transforming growth factor-beta family members through Smad proteins. Eur J Biochem 2000, 267:6954-6967.

7. Massague J, Chen YG: Controlling TGF-beta signaling. Genes Dev 2000, 14:627-644.

8. Crawford SE, Stellmach V, Murphy-Ullrich JE, Ribeiro SM, Lawler J, Hynes RO, Boivin GP, Bouck N: Thrombospondin-1 is a major activator of TGF-beta1 in vivo. Cell 1998, 93:11591170.

9. Robinson SD, Silberstein GB, Roberts AB, Flanders KC, Daniel $\mathrm{CW}$ : Regulated expression and growth inhibitory effects of transforming growth factor- $\beta$ isoforms in mouse mammary gland development. Development 1991, 113:867-878.

10. Barcellos-Hoff $\mathrm{MH}$, Ewan KB: Transforming growth factor-beta and breast cancer: mammary gland development. Breast Cancer Res 2000, 2:92-99.

11. Faure E, Heisterkamp N, Groffen J, Kaartinen V: Differential expression of TGF-beta isoforms during postlactational mammary gland involution. Cell Tissue Res 2000, 300:89-95.

12. Nguyen AV, Pollard JW: Transforming growth factor beta3 induces cell death during the first stage of mammary gland involution. Development 2000, 127:3107-3118.

13. Joseph H, Gorska AE, Sohn P, Moses HL, Serra R: Overexpression of a kinase-deficient transforming growth factor-beta typell receptor in mouse mammary stroma results in increased epithelial branching. Mol Biol Cell 1999, 10:12211234 .

14. Silberstein GB, Daniel CW: Reversible inhibition of mammary gland growth by transforming growth factor- $\beta$. Science 1987 , 237:291-293.

15. Pierce DFJ, Johnson MD, Matsui $Y$, Robinson SD, Gold LI, Purchio AF, Daniel CW, Hogan BLM, Moses HL: Inhibition of mammary duct development but not alveolar outgrowth during pregnancy in transgenic mice expressing active TGFB1. Genes Dev 1993, 7:2308-2317.

16. Jhappan $C$, Geiser AG, Kordon EC, Bagheri D, Hennighausen L, Roberts $A B$, Smith GH, Merlino G: Targeting of a transforming growth factor $\beta 1$ transgene to the pregnant mammary gland inhibits alveolar development and lactation. EMBO J 1993, 12: $1835-1845$.

17. Kordon EC, McKnight RA, Jhappan C, Hennighausen L, Merlino G, Smith GH: Ectopic TGF beta 1 expression in the secretory mammary epithelium induces early senescence of the epithelial stem cell population. Dev Biol 1995, 168:47-61.

18. Gorska AE, Joseph H, Derynck R, Moses HL, Serra R: Dominantnegative interference of the transforming growth factor beta type II receptor in mammary gland epithelium results in alveolar hyperplasia and differentiation in virgin mice. Cell Growth Differ 1998, 9:229-238.

19. Daniel CW, Silberstein GB, Van Horn K, Strickland P, Robinson S: TGF-beta 1-induced inhibition of mouse mammary ductal growth: developmental specificity and characterization. Dev Biol 1989, 135:20-30.

20. Dunker N, Krieglstein K: Targeted mutations of transforming growth factor-beta genes reveal important roles in mouse development and adult homeostasis. Eur J Biochem 2000, 267:6982-6988.

21. Wakefield LM, Yang Y, Dukhanina O: Transforming growth factor-beta and breast cancer: lessons learned from genetically altered mouse models. Breast Cancer Res 2000, 2:100106.

22. Soriano JV, Pepper MS, Orci L, Montesano R: Roles of hepatocyte growth factor/scatter factor and transforming growth factor beta1 in mammary gland ductal morphogenesis. $J$ Mam Gland Biol Neoplasia 1998, 3:133-150.

23. Kamalati T, Niranjan B, Yant J, Buluwela L: HGF/SF in mammary epithelial growth and morphogenesis: in vitro and in vivo models. J Mam Gland Biol Neoplasia 1999, 4:69-77.

24. Mieth M, Boehmer FD, Ball R, Groner B, Grosse R: Transforming growth factor-beta inhibits lactogenic hormone induction of beta-casein expression in $\mathrm{HC} 11$ mouse mammary epithelial cells. Growth Factors 1990, 4:9-15. 
25. Robinson SD, Roberts $A B$, Daniel CW: TGF beta suppresses casein synthesis in mouse mammary explants and may play a role in controlling milk levels during pregnancy. J Cell Biol 1993, 120:245-251.

26. Sachs M, Brohmann H, Zechner D, Muller T, Hulsken J, Walther I, Schaeper U, Birchmeier C, Birchmeier W: Essential role of Gab1 for signaling by the c-Met receptor in vivo. J Cell Biol 2000, 150:1375-1384.

27. Sergeant N, Lyon M, Rudland PS, Fernig DG, Delehedde M: Stimulation of DNA synthesis and cell proliferation of human mammary myoepithelial-like cells by hepatocyte growth factor/scatter factor depends on heparan sulfate proteoglycans and sustained phosphorylation of mitogen-activated protein kinases p42/44. J Biol Chem 2000, 275:17094-17099.

28. Niemann C, Brinkmann V, Spitzer E, Hartmann G, Sachs M, Naundorf H, Birchmeier W: Reconstitution of mammary gland development in vitro: requirement of c-met and c-erbB2 signaling for branching and alveolar morphogenesis. J Cell Biol 1998, 143:533-545.

29. Niranjan B, Buluwela L, Yant J, Perusinghe N, Atherton A, Phippard D, Dale T, Gusterson B, Kamalati T: HGF/SF: a potent cytokine for mammary growth, morphogenesis and development. Development 1995, 121:2897-2908.

30. Firon M, Shaharabany M, Altstock RT, Horev J, Abramovici A, Resau JH, Vande Woude GF, Tsarfaty I: Dominant negative Met reduces tumorigenicity-metastasis and increases tubule formation in mammary cells. Oncogene 2000, 19:2386-2397.

31. Ponzetto C, Pante G, Prunotto C, leraci A, Maina F: Met signaling mutants as tools for developmental studies. Int J Dev Biol 2000, 44:645-653.

32. Yant J, Buluwela L, Niranjan B, Gusterson B, Kamalati T: In vivo effects of hepatocyte growth factor/scatter factor on mouse mammary gland development. Exp Cell Res 1998, 241: 476-481.

33. Werner $F$, Jain MK, Feinberg MW, Sibinga NE, Pellacani A, Wiesel P, Chin MT, Topper JN, Perrella MA, Lee ME: Transforming growth factor-beta 1 inhibition of macrophage activation is mediated via Smad3. J Biol Chem 2000, 275:36653-36658.

34. Chong $\mathrm{H}$, Vodovotz $\mathrm{Y}$, Cox GW, Barcellos-Hoff MH: Immunocytochemical localization of latent transforming growth factorbeta1 activation by stimulated macrophages. J Cell Physiol 1999, 178:275-283.

35. Barcellos-Hoff $\mathrm{MH}$ : Radiation-induced transforming growth factor beta and subsequent extracellular matrix reorganization in murine mammary gland. Cancer Res 1993, 53: 3880-3886.

36. Miettinen PJ, Ebner R, Lopez AR, Derynck R: TGF-beta induced transdifferentiation of mammary epithelial cells to mesenchymal cells: involvement of type I receptors. J Cell Biol 1994, 127:2021-2036.

37. Klinowska TC, Soriano JV, Edwards GM, Oliver JM, Valentijn AJ, Montesano R, Streuli $\mathrm{CH}$ : Laminin and beta1 integrins are crucial for normal mammary gland development in the mouse. Dev Biol 1999, 215:13-32.

38. Larsson J, Goumans MJ, Sjostrand LJ, van Rooijen MA, Ward D, Leveen P, Xu X, ten Dijke P, Mummery CL, Karlsson S: Abnormal angiogenesis but intact hematopoietic potential in TGF-beta type I receptor-deficient mice. EMBO J 2001, 20:1663-1673.

39. Dankort DL, Muller WJ: Signal transduction in mammary tumorigenesis: a transgenic perspective. Oncogene 2000, 19: 1038-1044.

40. Chakravarthy D, Green AR, Green VL, Kerin MJ, Speirs V: Expression and secretion of TGF-beta isoforms and expression of TGF-beta-receptors I, II and III in normal and neoplastic human breast. Int J Oncol 1999, 15:187-194.

41. Plath A, Einspanier R, Peters F, Sinowatz F, Schams D: Expression of transforming growth factors alpha and beta- 1 messenger RNA in the bovine mammary gland during different stages of development and lactation. J Endocrinol 1997, 155: 501-511.

42. Huynh H, Beamer W, Pollak M, Chan TW: Modulation of transforming growth factor beta1 gene expression in the mammary gland by insulin-like growth factor I and octreotide. Int J Oncol 2000, 16:277-281. 